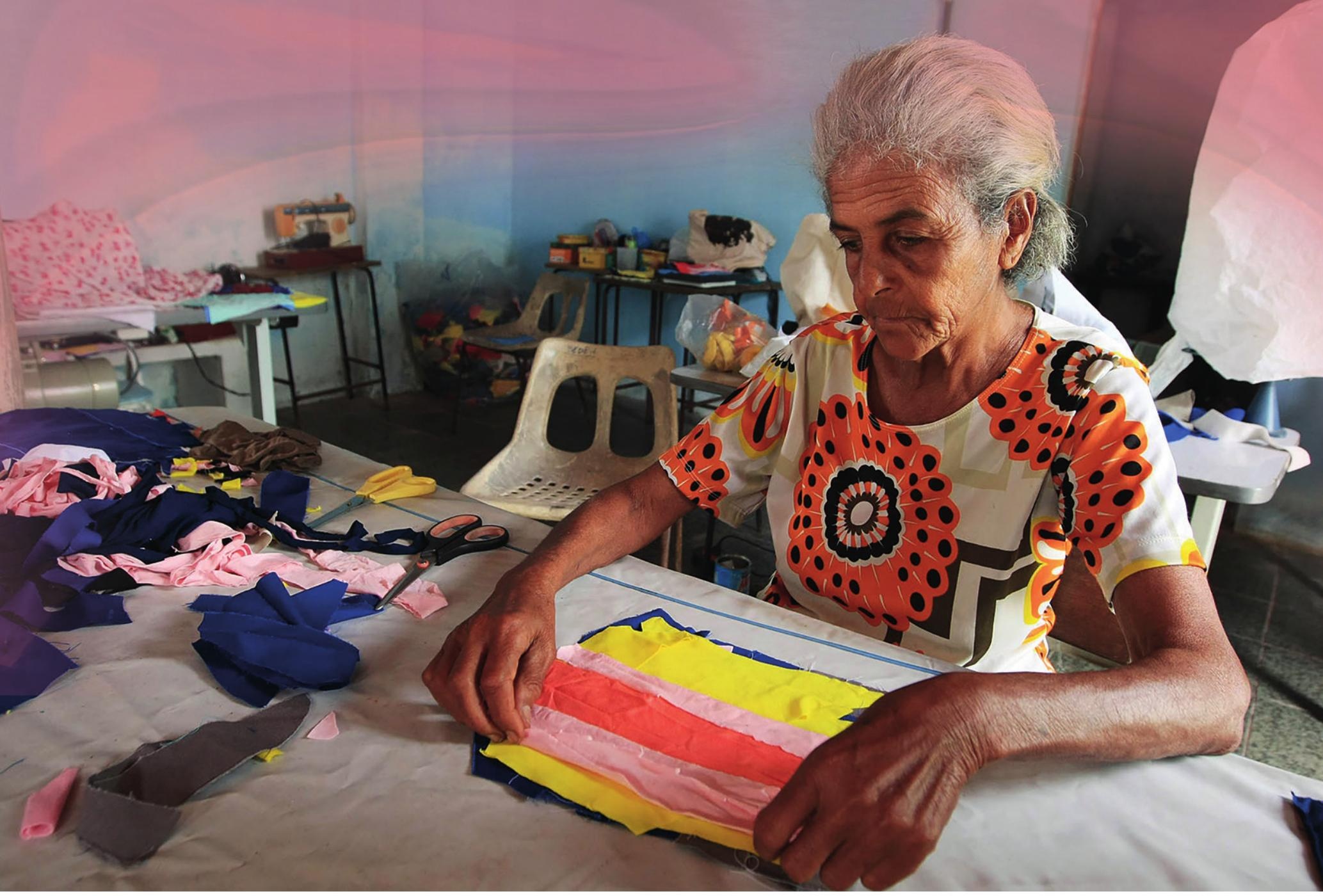

\title{
MULHER EMPREENDEDORA: FORTALECIMENTO DE PRÁTICAS DE EMPREENDEDORISMO E PARTICIPAÇÃO SOCIAL
}

\section{RESUMO}

O programa de extensão intitulado Mulher Empreendedora: garantindo espaço de construção do conhecimento, saberes e participação social na comunidade surgiu das necessidades das relações de gênero, em virtude do constante crescimento do empreendedorismo feminino. $\mathrm{O}$ objetivo do projeto foi discutir a experiência vivenciada pela equipe do programa durante o ano de 2014, cujo público-alvo foi constituído por mulheres gerentes de empresas, horteiras, empregadas das fábricas de costuras, catadoras de lixo e auxiliares de serviços gerais, em locais da comunidade urbana e rural do município de Santa Cruz, Rio Grande do Norte. Esse programa foi dividido em cinco ações de extensão, que se complementam: I) Capacitação de empresárias da cidade de Santa Cruz/RN: construção da cartilha educativa Conhecer para Empreender; II) Capacitação para resgate de saberes e práticas em mulheres horteiras com enfoque econômico, profissional e em saúde; III) Mulheres e cooperativismo: capacitação sobre produção com qualidade nas fábricas de costura de Santa Cruz/RN; IV) Capacitação

Tainara Lôrena dos Santos Ferreira (tainara lorena@hotmail.com - FACISA/UFRN), Fábia Barbosa de Andrade (fabiabarbosabr@ yahoo.com.br - Professora Adjunto III/UFRN). 
em associações de moradores: o espaço político e de atuação de mulheres empreendedoras na zona urbana e rural; V) Biossegurança: capacitação de auxiliares de serviços gerais e catadores de lixo na coleta seletiva e manejo de resíduos. Estas atividades ocorreram em parceria com vários órgãos e instituições municipais públicas de Santa Cruz, bem como docentes, discentes e técnicos da Faculdade de Ciências da Saúde do Trairi/Universidade Federal do Rio Grande do Norte. Ressalta-se que o programa veio ao encontro das deficiências das mulheres no mercado de trabalho de modo a contribuir para o crescimento de sua autonomia, empreendedorismo e participação social na comunidade.

Palavras-chave: Mulheres. Gênero e Saúde. Educação em Saúde.

\section{INTRODUÇÃO}

O mercado de trabalho tem passado por constantes mudanças e inovações, de modo a evidenciar o surgimento de alguns fatos mais marcantes na sociedade brasileira, como a inserção crescente da mulher no mercado de trabalho, fato este, explicado pela combinação de fatores econômicos, culturais e sociais. A evidência desse aumento significativo da presença das mulheres na esfera econômica demonstra um movimento no âmbito local, regional e nacional, que revela uma mudança no processo de transformação das expectativas de vida pessoal, nas relações familiares e nas demandas por serviços públicos ${ }^{1}$.

Ao longo dos anos, a história da mulher na sociedade e no mercado de trabalho tem se tornado assunto importante, uma vez que a atuação feminina esteve sempre relacionada com atividades referentes à manutenção da casa e da família, e vista como um apoio ao homem. Apesar de os cuidados com os filhos, marido e casa ainda fazerem parte do mundo feminino, as mulheres adicionaram também diversos papéis profissionais com esta busca na equiparação dos gêneros (CARVALHO; ALMADA; MACHADO, 2006).

No Brasil, as mulheres representam a maior parcela da população, de modo que estão inseridas e exercem influência nos diversos setores do país como na economia, uma vez que muitas famílias têm como provedora parcial ou total de renda uma mulher, e esta, tem sua vida permeada por eventos que a condicionam a uma maior suscetibilidade à condições mórbidas de origem biológicas, psíquicas e sociais como o evento da puberdade marcado por alterações hormonais, bem como os ciclos menstruais, a gravidez e as modificações corporais decorrentes desta, o parto, o processo de envelhecimento e o climatério, entre outros.

A mulher da atualidade consegue equilibrar todos os pontos da sua vida, sendo eles na área pessoal, familiar e profissional. Por este motivo, muitas conseguem concorrer a cargos que eram ocupados somente por homens como, por exemplo, cargos políticos, militares, nos tribunais superiores, nos ministérios, no topo de grandes empresas, comandando tropas, perfurando poços de petróleo e outros, ou seja, não existem mais espaços delimitados onde $\mathrm{o}$ homem ou a mulher possa atuar, na verdade, o que importa é a qualificação do profissional independentemente do gênero.

Assim, a busca e o acesso das mulheres à educação e o desenvolvimento de novos perfis de competência profissional e gerencial podem ser compreendidos como uma resposta à necessidade de acompanhar o novo cenário laboral (MENDEZ, 2005). Este cenário coloca a mulher em um dualismo: primeiramente, temos aquelas que dão prioridade ao lado profissional, as chamadas de mulheres de carreira; e há ainda as que dão prioridade tanto ao trabalho quanto à família, chamadas de mulheres de carreira e de família, as quais não podem se desvincular desse papel familiar 
tão facilmente, por se tratar de uma herança histórica e cultural.

O empreendedorismo constitui um modelo com enfoque na dimensão humana, social e sustentável e acontece por meio de redes e parcerias, contribuindo para a organização do sistema social e possibilitando melhorias na qualidade de vida da população envolvida, uma vez que estimula a participação ativa dos indivíduos em sua própria história. Nessa perspectiva, empreender torna-se mais que uma forma de aumentar a rentabilidade, traz benefícios que (re)significam a sua vida a partir da oportunidade de modificar cenários de vulnerabilidade social, estimular as pessoas a desenvolverem seus talentos e desenvolver o protagonismo ativo como promotor de mudanças e transformação.

\section{OBJETIVOS}

O estudo relatado neste artigo teve por objetivo discutir a experiência vivenciada pela equipe do programa de extensão Mulher Empreendedora, realizado durante o ano de 2014, que teve como público-alvo as mulheres gerentes de empresas, horteiras, empregadas

das fábricas de costuras, catadoras de lixo e auxiliares de serviços gerais, em locais da comunidade urbana e rural de Santa Cruz/RN, a citar: associações urbanas e rurais, unidades básicas de saúde, escolas, fábricas, hospitais e espaços sociais de convivência da comunidade.

\section{METODOLOGIA}

Este trabalho trata-se de um estudo do tipo exploratório e descritivo de abordagem ancorada no relato de experiência da equipe do programa de extensão, intitulado Mulher Empreendedora: garantindo espaço de construção do conhecimento, saberes e participação social na comunidade, desenvolvido na cidade de Santa Cruz/RN. Para trabalhar a temática mulheres e relações de gênero, fez-se uso do método da pesquisa-ação aliada ao Problem-based learning (PBL) - ou aprendizado baseado em problemas (ABP). PBL é uma abordagem que vem sendo amplamente difundida como uma estratégia para um novo e efetivo processo de educação dos profissionais de saúde (COELHO-FILHO; SOARES; GARMO E SÁ, 1998). Essa abordagem tem o propósito de criar hábitos de estudo e de pensamento através do método da experiência reflexiva, melhorar o desempenho escolar dos alunos, promovendo autonomia de aprendizagem e de trabalho em equipe, tal como se espera que ocorra na vida profissional. É primordial, na PBL, que seja apresentado o problema para

solução, pelo aluno, devendo ser relevante ao exercício profissional e criando condições para o aluno perceber-se mediante determinada questão ou situação-problema e questionar-se (RIBEIRO, 2008).

A PBL representa, portanto, um avanço em relação ao ensino transmissivo predominante no meio universitário, contribuindo para formar hábitos de aprendizagem autônoma, iniciativa e capacidade resolutiva, tendo como mérito principal situar o conteúdo de aprendizagem em contextos significativos de ação (ou de exercício profissional), motivando o aluno e fazendo com que ele crie senso de responsabilidade pela solução dos problemas além de ajudar a superar a tão criticada separação entre a formação acadêmica e a realidade concreta, entre teoria e prática (FREITAS, 2012).

As ações estiveram ancoradas ainda no método da pesquisa-ação que vem buscar soluções dos problemas situacionais, oferecendo aos pesquisadores e aos grupos pesquisados, os meios de se tornarem capazes de respondê-los 
com maior eficiência, particularmente, por meio da ação transformadora. Para Thiollent (2011, p. 20), trata-se de:

Um tipo de pesquisa social com base empírica que é concebida e realizada em estreita associação com uma ação ou com a resolução de um problema coletivo no qual os pesquisadores e os participantes representativos da situação ou do problema estão envolvidos de modo cooperativo ou participativo.

Pode-se destacar que a pesquisa-ação tem como objetivo desenvolver o conhecimento e a compreensão como parte da prática, sendo uma maneira de se fazer pesquisa em situações em que também se é uma pessoa da prática e se deseja melhorar a compreensão desta (ENGEL, 2000).
No que se refere a este trabalho, a execução das ações ocorreu por meio de abordagens educativas e de capacitação para os cinco projetos do programa, como uma possibilidade de promover a satisfação do usuário, a avaliação das condições de saúde das mulheres e a atuação dos discentes na promoção da saúde destas, de modo que os participantes dessas ações pudessem adquirir experiência profissional, além de aprimorarem seus conhecimentos e vivências na comunidade, o que lhes possibilitará o aperfeiçoamento na formação do perfil do profissional egresso crítico, reflexivo segundo as diretrizes curriculares nacionais dos cursos, com foco na teoria da problematização e, assim, empoderamento e fortalecimento dessa clientela.

\section{AÇõES REALIZADAS PARA ALCANÇAR OS OBJETIVOS}

$\mathrm{Na}$ execução do projeto foram realizadas as atividades previstas as ações de extensão intituladas: I) Capacitação de empresárias da cidade de Santa Gruz/RN: construção da cartilha educativa Conhecer para Empreender; II) Capacitação para resgate de saberes e práticas em mulheres horteiras com enfoque econômico, profissional e em saúde; III) Mulheres e cooperativismo: capacitação sobre produção com qualidade nas fábricas de costura de Santa Cruz/RN; IV) Capacitação em associações de moradores: o espaço político e de atuação de mulheres empreendedoras na zona urbana e rural; V) Biossegurança: capacitação de auxiliares de serviços gerais e catadores de lixo na coleta seletiva e manejo de resíduos.

No que concerne à ação de extensão I realizada com empresárias, teve-se como resultado a realização de capacitações para administrar suas empresas sobre práticas corretas de negociação e com vistas à rentabilidade, a realização de práticas de ginástica laboral para prevenção de desgaste físico e emocional no ambiente de trabalho para mulheres, a sensibilização das funcionárias das empresas para realização de exames periódicos e rastreamento de fatores de risco para adoecimento, bem como a troca mútua de conhecimentos por meio de ações de educação em saúde para prevenção e controle do estresse, um agravo considerado prevalente no mundo empresarial e outras temáticas pertinentes.

Quanto às oficinas da ação de saúde II, os resultados foram realizados a partir das oficinas para mulheres horteiras sobre o manuseio de qualidade das hortaliças e sua importância na feira livre, assim como sobre prevenção de doenças através dos alimentos contaminados, capacitação sobre as práticas de higiene, de saúde e prevenção de contaminação nas hortaliças, atividades sobre as práticas de saúde. Além disso, ocorreu a realização de exames preventivos e consultas de saúde sobre o rastreamento de fatores de risco, bem como sinais e sintomas, que podem ser desencadeadores de doenças; posteriormente, houve o aperfeiçoamento do processo de elaboração dos produtos já existentes.

Sobre a ação de extensão III, foram realizadas com as costureiras oficinas sobre a 
produção de um melhor produto, tendo como destaque a oficina $A$ melhor forma de costurar e se cuidar, na qual foram desenvolvidas práticas de autocuidado associado ao conhecimento das mulheres sobre sua profissão e sua participação na sociedade. Além disso, foram realizadas rodas de conversas com as funcionárias das fábricas, identificando fragilidades, potencialidades e conhecimentos em comum, bem como sobre o cooperativismo e a formação de grupos profissionais de mulheres sob o enfoque de gênero para fins de fortalecimento da força de trabalho feminino e maior participação na sociedade.

No que diz respeito à ação de extensão IV com mulheres de associações de moradores da zona rural e urbana do município, esta se deu a partir das metas estabelecidas. Nela, foram realizadas ações educativas sobre a participação social e econômica das mulheres na comunidade, práticas de prevenção de doenças de mulheres associadas revelando a real importância da adesão às práticas de vida saudáveis, assim como sobre sua participação no mercado de trabalho e expressão da força de trabalho feminina e o fortalecimento das associações, de modo a sensibilizá-las; se estimulou ainda a formação de grupos de mulheres empreendedoras para que estas possam expandir o conhecimento, competência e habilidades adquiridas.

Quanto à ação de extensão V, com mulheres que desempenham a função de catadoras de lixo e Auxiliar de Serviços Gerais (ASG), foram realizadas oficinas e rodas de conversa sobre a biossegurança e o uso de equipamentos de proteção individual e coletiva; ocorreram, também, práticas de ginástica laboral e consultas de saúde para mulheres que executam atividades laborais que podem oferecer risco a saúde física, emocional e psíquica. E, por fim, houve a discussão sobre direitos e deveres das mulheres para buscar a melhoria da qualidade de vida nas atividades de serviços gerais e catadores de lixo na coleta seletiva e manejo de resíduos, assim como sobre a formação de grupos de mulheres empreendedoras sobre a educação da coleta seletiva de lixo.

Além das ações de extensão descritas, foram realizadas ações únicas de saúde com o grupo de artesãs, costureiras, horteiras e a comunidade da zona rural. Entre tais intervenções, foram efetivados serviços de verificação de pressão arterial, nível de glicemia, medição de índice de massa corporal (IMC), orientação sobre alimentação saudável e hábitos alimentares, análise ergonômica e orientações preventivas para diminuição e prevenção do aparecimento de dores corpóreas; foi observado que essas ações tiveram uma participação ativa do públicoalvo. Além do público em foco, destaca-se que foi realizada ação de saúde para toda a população de Santa Cruz, com atendimentos de saúde e orientações pertinentes. Cabe ressaltar ainda, como resultado e produto do programa, a realização do I Workshop: Aprendendo a Empreender, realizado com as mulheres público deste programa, discutindo a formação empreendedora e a perspectiva das relações de gênero.

\section{SOBRE AS AÇÕES}

O programa Mulher Empreendedora vem garantir uma maior aproximação da academia com os demais segmentos da sociedade feminina de Santa Cruz/RN, uma vez que possibilitou o fortalecimento da relação "mulheres e o mercado de trabalho" pelo empoderamento proposto, assim como por estimular a participação social das mulheres em associações, comércios,

fábricas e toda comunidade por meio das oficinas e resultados supracitados, com temas prioritários para as mulheres participantes e o fortalecimento da linha de mulheres e relações de gênero. Percebeu-se, portanto, que a educação continuada, o fortalecimento das práticas de saúde e o empoderamento feminino traz consigo a oportunidade de modificar cenários, 
principalmente, no que diz respeito ao fortalecimento das mulheres nas comunidades.

Entende-se, ainda, que a educação é um processo dinâmico e contínuo de construção do conhecimento, que leva à criação de compromisso pessoal e profissional, capacitando para a transformação da realidade. A educação continuada atua no desenvolvimento da competência pessoal, a fim de promover, além da capacitação técnica específica dos sujeitos, a aquisição de novos conhecimentos, conceitos e atitudes (PASCHOAL; MANTOVANI; MEIER, 2007).

Desse modo, faz-se necessário reconhecer que a concretização de uma educação permanente em diversos cenários sociais traz inúmeros benefícios, os quais serão responsáveis por transformar vidas, modificar cenários de vulnerabilidade social, aumentar a oportunidade das pessoas desenvolverem seus talentos e construírem uma história de cidadania e superação. E para isso ocorrer, é preciso a realização de ações baseadas no empoderamento das pessoas no intuito de fortalecer os indivíduos socialmente, politicamente, economicamente e também do ponto de vista cidadão.

Sabe-se que, neste processo, a indissociabilidade entre democracia e de democratização do saber, a universidade passa a ser também uma instituição social, uma vez que a educação e a cultura, como direitos dos cidadãos, são parte constitutiva da cidadania. A relação entre universidade e sociedade justifica o fato de que, desde seu surgimento, a universidade pública tenha sido uma instituição social, fundada em uma prática social de reconhecimento público, cuja legitimidade e atribuições lhe conferem autonomia perante outras instituições sociais.

Na perspectiva de mulheres e o mercado de trabalho, ressalta-se que a atuação da mulher nos diversos cenários da comunidade nos remete a perceber o conhecimento adquirido em suas experiências diárias, e a observar a participação feminina no mercado de trabalho, seu estilo de vida, sua família, sua saúde e a sua satisfação. A legitimação dessas mulheres como sujeitos sociais foi conseguida, sobretudo, a partir do seu compromisso com uma luta organizada em busca de seus direitos e definição de seu espaço na sociedade. A luta organizada enriqueceu as práticas associativas femininas permitindo-lhes tratar das demandas e dos problemas derivados da condição de gênero.

Sabe-se que a força do empreendedorismo feminino está em constante crescimento, no entanto, ainda há muitos desafios postos que também devem ser vistos de modo a proporcionar uma melhor qualificação das mulheres em cenários que, anteriormente, não eram por elas ocupados; além de medidas que proporcionem a estas uma melhor qualidade de vida e qualidade no ambiente de trabalho. Para tanto, destacam-se as atividades vivenciadas e propostas pelo programa, uma vez que propõem capacitações de empreendedorismo, preparam essas mulheres para o cenário econômico, discutem a perspectiva de gênero e mercado de trabalho, planejamento, e as estimulam a buscar independência, e melhorias na sua qualidade de vida e saúde, por meio de ações de saúde e educação em saúde, oficinas, capacitação, entre outros.

Nessa perspectiva, a capacitação é uma das formas de se promover a educação e a autonomia dos sujeitos, e se torna essencial para o desenvolvimento de melhores condições de trabalho. Esse processo de capacitação necessita de ser bem compreendido de uma forma dinâmica e introduzidas estratégias de educação em economia e gestões empresariais, sendo necessário um bom entendimento desses ensinamentos no ambiente empresarial para que se tenha um melhor resultado perante seus consumidores. Dessa maneira, a conscientização da necessidade de capacitação e a busca de novas alternativas de desenvolvimento gerencial para empresários tornam-se absolutamente necessárias para a organização e desenvolvimento da empresa.

Aimportância de as empresas desenvolverem 
diferentes experiências de apoio tem como objetivo estender sua perspectiva de vida. Uma das alternativas viáveis para suportar a criação e o desenvolvimento das empresas está relacionada à organização de propostas educacionais, as quais visem tanto estimular o espírito empreendedor quanto habilitar proprietários e gerentes na análise de ferramentas de gestão que aumentem a eficácia empresarial.

A urgência de maior produtividade, associada à redução da quantidade dos trabalhadores e à pressão do tempo, o aumento da complexidade das tarefas, além de objetivos não alcançados e as relações de trabalho difíceis, podem gerar tensão, fadiga e esgotamento profissional, constituindo-se em fatores psicossociais responsáveis por situações de estresse relacionado com o trabalho, ocasionando grande impacto no desempenho das atividades (GUIMARÃES, 2006).

Para que de fato ocorra uma evolução nas condições de trabalho de forma eficiente e que visem uma melhoria na qualidade de vida do indivíduo, o ambiente de trabalho deve gerar bem-estar a estes trabalhadores e estes devem estar capacitados a exercerem sua profissão com condições favoráveis a desempenhar o melhor serviço possível, além de proporcionar uma atividade prazerosa e saudável, aumentando assim a sua rentabilidade.

A habilitação dos empresários e gerentes se constitui em desenvolver e estimular uma série de comportamentos, atitudes e atributos relacionados à capacidade para estabelecer e perseguir objetivos, assumir riscos em ambientes imprevisíveis, solucionar problemas e conflitos de forma criativa, agir com independência e iniciativa, entre outros. Além disso, merecem destaque as orientações sobre as formas de prevenção do adoecimento laboral, as quais podem evitar, muitas vezes, o afastamento dos funcionários de seu trabalho e, consequentemente, maior ônus à vida econômica daquela empresa, bem como para o indivíduo e família do trabalhador que é acometido por alguma patologia.
Com o passar dos tempos, o modo de trabalhar teve suas devidas alterações, com novas formas de organização da produção, novas tecnologias, diminuição das contratações, ampliação da jornada e precariedade das relações de trabalho e, a partir dessas mudanças, houve o aumento das doenças e dos acidentes relacionados ao trabalho (PRAZERES; NAVARO, 2011). Considerando tais aspectos, ressalta-se a importância da educação continuada que se constitui como uma prática na qual o desenvolvimento pessoal e profissional dos trabalhadores é fundamental para o aperfeiçoamento das habilidades, bem como maior visão da realidade em que estão inseridos, visando uma construção de conhecimentos.

Nesse sentido, a conscientização da necessidade de capacitação e a busca de novas alternativas de desenvolvimento gerencial para empresários tornam-se absolutamente necessárias para a organização e desenvolvimento da empresa. O desenvolvimento desses empresários envolve, portanto, uma convergência de aspectos que devem ser compreendidos e analisados de forma integrada, tendo-se consciência das suas características específicas e das suas necessidades (TEIXEIRA; MORRISON, 2004).

A educação continuada é um conjunto de práticas que tem por objetivo mudanças nos modelos predominantes de formação e atenção à saúde. Proporciona ao indivíduo a construção de conhecimentos na busca de capacidade profissional e desenvolvimento pessoal, de acordo com a realidade institucional e social (BEZERRA, 2003). Sabe-se que a educação continuada é de responsabilidade dos serviços e das pessoas, por meio da qual são utilizadas experiências do trabalho, família e sociedade na tentativa de educar continuamente (PASCHOAL; MANTOVANI; MEIER, 2007). Além de capacitar o indivíduo para vida, capacita-o para mudanças desejadas pela instituição, desenvolvendo a pessoa e o profissional (KURGGANT, 1993). 
Nesse sentido, faz-se necessário incentivar a capacitação sobre as medidas de melhor orientação e norteamento das mulheres horteiras para o mercado de trabalho, para que estas possam atuar e comercializar na feira livre de Santa Cruz, para fins de empreendedorismo. Além desse aspecto, é necessário que as mulheres horteiras tenham conhecimento sobre práticas de higiene, saúde, cuidado com o uso de agrotóxicos e danos à saúde; essas mulheres também devem reconhecer que podem ser multiplicadores do processo de educação permanente.

Dessa maneira, o desenvolvimento das ações de extensão I, II, III, IV e V foi de extrema importância para a cidade de Santa Cruz, uma vez que estas possibilitaram atividades com a finalidade de formar mulheres empreendedoras, cidadãs e boas administradoras, garantindo a atuação de maneira positiva, tanto em termos individuais quanto coletivos, e fortalecer a prática de empreendedorismo já desenvolvida, por meio de capacitações e ações contínuas de educação, assim como prover ações que primem pelo bem-estar dessas trabalhadoras, possibilitando a diminuição do acometimento de riscos e agravos, por meio dos atendimentos de saúde que propiciem um melhor rendimento nos seus locais de trabalho e uma melhor qualidade de vida.

\section{CONCLUSÕES}

A execução do programa de extensão Mulher empreendedora teve como fio condutor indissociabilidade entre ensino, pesquisa e extensão, uma vez que a equipe conseguiu vivenciar as atividades no âmbito da comunidade e realizar capacitações, oficinas, palestras, dinâmicas em temas de interesse da proposta e em consonância com esta, para fins de construção de saberes, promoção de melhorias de condições de vida, reduzindo as desigualdades sociais e fortalecimento da educação continuada na comunidade. Além disso, foi primordial ensinar a temática da prevenção de doenças, imprescindível para atuação de qualidade no trabalho de mulheres, pois à medida que adoecem, precisam se afastar de suas atividades laborais.

Nessa perspectiva, o desenvolvimento desse programa de extensão com o grupo de mulheres gerentes de empresas, horteiras, empregadas das fábricas de costuras, catadoras de lixo e auxiliares de serviços gerais na cidade de Santa Cruz-RN permitiu a realização de ações em saúde e educação em saúde de modo a promover o melhor rendimento profissional por meio da melhor qualidade de vida, bem como ajudou no quesito de convívio social e a ter uma melhor relação interpessoal no trabalho, tornando mais agradável o ambiente em que essas trabalhadoras passam maior parte do dia.

A busca pela interdisciplinaridade, intersetorialidade e a utilização de metodologias ativas, por meio da utilização de cenários diversificados de práticas em serviços de saúde loco-regionais, auxiliaram o fortalecimento de uma articulação no ensino-serviço-comunidade. Nesse sentido, a integração ensino-serviço-comunidade constituiu uma oportunidade de transformar o espaço de produção de conhecimento em espaço de aprendizagem. Foi a partir dessas ações educativas e de capacitações que se construiu o conhecimento do saber dessas empreendedoras, proporcionando-lhes uma melhor atuação acompanhada do alcance de metas almejadas pela vida no trabalho, na saúde e na família, encontrando a participação e a contribuição do gênero feminino no empreendedorismo, tornando-a mais livre, atuante e conhecedora da vida, e também da saúde e do trabalho, uma vez que o adoecimento causaria impacto no cotidiano laboral dessa mulher para o desenvolvimento da empresa. 
Cabe destacar o fortalecimento da educação continuada na comunidade, o qual aprimorou o mercado de trabalho do qual esta faz parte e possibilitou a construção de saberes, conhecimentos, e empoderou a participação social, permitindo melhorar as condições de vida e fortalecendo o ensino na temática da prevenção de doenças para a uma melhor atuação no seu campo de trabalho. Com a ajuda das oficinas e ações de saúde, pode-se resgatar a busca da identidade social dessas mulheres, da sua liberdade laboral e da expressão no mercado de trabalho, promovendo a educação, saúde e direitos garantidos.

\section{ENTREPRENEURIAL WOMAN: ENTREPRENEURSHIP PRACTICES STRENGTHENING AND SOCIAL PARTICIPATION}

\section{ABSTRACT}

The outreach program entitled Women Entrepreneurs: ensuring space for the construction of knowledge, skills and social participation in the community arose from the needs of gender relations, and because of the constant growth of female entrepreneurship. Thus, this study aims to discuss the experience lived by program staff during the year 2014, whose target audience consisted of women managers of companies, horteiras, employed the seams plants, garbage pickers and auxiliary of general services, in local urban and rural community of Santa Cruz, Rio Grande do Norte. This program was divided of five extension actions, which have complementary relationship, namely: I) entrepreneurs Training of the city of Santa Cruz/RN: Construction educational booklet Knowing to undertake; II) Training for rescue knowledge and practices in horteiras women with economic focus, professional and health; III) Women and cooperatives: training on production quality in sewing factories Santa Cruz/RN; IV) Training in neighborhood associations: the political space and role of women entrepreneurs in urban and rural areas; V) Biosafety: training of general services assistants and garbage collectors in selective collection and waste management. These activities will take place in partnership with various public agencies and municipal institutions of Santa Cruz, as well as teachers, students and technicians of the Faculty of Health Sciences of Trairi / Federal University of Rio Grande do Norte. It is noteworthy that this program meets the shortcomings of women in the labor market so as to contribute to the growth of these women, in the sense of autonomy, entrepreneurship and social participation in the community.

Keywords: Women. Gender and Health. Health Education. 


\section{REFERÊNCIAS}

BEZERRA, A. L. Q. O contexto da educação continuada em enfermagem. São Paulo:

Ed. Lemar e Martinari, 2003.

CARVALHO, F. K. A.; ALMADA, I. W. MACHADO, D. D. P. N. Gênero e gestão universitária: as mulheres em cargos de chefia nos quarenta e dois anos da Universidade Regional de Blumenau. In: COLÓQUIO INTERNAGIONAL SOBRE GESTÃO UNIVERSITÁRIA NA AMÉRICA DO SUL, 6., 2006, Blumenau, SC. Anais... Blumenau, SC: UFSG, 2006.

COELHO-FILHO, J. M.; SOARES, S. M. S.; CARMO e SÁ, H. L. Problem-based learning: application and possibilities in Brazil, São Paulo, Medical Journal, v. 116, n. 4, p. 1784-1785, july/aug. 1998.

ENGEL, G. I. Pesquisa-ação. Educar, Curitiba, n. 16, p. 181-191, 2000.

FREITAS, R. A. M. M. Ensino por problemas: uma abordagem para o desenvolvimento do aluno. Educ. Pesqui., São Paulo, v. 38, n. 2, 2012.

GUIMARÃES, L. A. M. Fatores psicossociais de risco no trabalho. In: Anais do 2. Congresso de Saúde Mental, Goiânia, p.99-110, 2006.

KURGGANT, P. Educação continuada: caminho para a qualidade. Rev Paul Enferm., v. 12, n. 2, p. 66-71, 1993.

MENDEZ, N. P. Do lar para as ruas: capitalismo, trabalho e feminismo. Mulher e Trabalho, v. 5, p. 51-63, 2005. Disponível em: <http://revistas.fee.tche.br/index.php/mulheretrabalho/ article/view/2712/3035>. Acesso em: 26 nov. 2015.

PASCHOAL, A. S.; MANTOVANI, M. F.; MEIER, M. J. Percepção da educação permanente, continuada e em serviço para enfermeiros de um hospital de ensino. Rev. esc. enferm. USP, São Paulo, v. 41, n. 3, p. 478-484, 2007.

PRAZERES, T. J.; NAVARRO, V. L. Na costura do sapato, o desmanche das operárias: estudo das condições de trabalho e saúde das pespontadeiras da indústria de calçados de Franca, São Paulo, Brasil. Cad. Saúde Pública, v. 27, n. 10, p. 1930-1938, 2011. Disponível em: <http:// www.scielo.br/pdf/csp/v27n10/06.pdf>. Acesso em: 21 mar. 2013. 
RIBEIRO, L. R. G. Aprendizagem baseada em problema (PBL): uma experiência no ensino superior. São Carlos: EduFSCar, 2008.

TEIXEIRA, R. M.; MORRISON, A. Desenvolvimento de empresários em empresas de pequeno porte do setor hoteleiro: processo de aprendizagem, competências e redes de relacionamento. Rev. adm. contemp., Curitiba, v. 8, n. 1, mar. 2004. Disponível em: <http://www.scielo. br/scielo.php? script $=$ sci_arttext\&pid $=$ S $141565552004000100006 \& \operatorname{lng}=$ en\&nrm $=$ iso $>$. Acesso em: 21 mar. 2013.

THIOLLENT, M. Metodologia da pesquisa-ação. 18. ed. São Paulo: Cortez, 2011. 
